\title{
Uso de tecnologias no ensino de Matemática nos Anos Iniciais do Ensino Fundamental: um Estado da Arte
}

\author{
El uso de tecnologías en la enseñanza de Matemáticas en los Años \\ Iniciales del Nivel Primario: un Estado del Arte
}

\author{
The Use of Technology in Mathematics Teaching in the Early Years of \\ Elementary School: a State of the Art
}

Thaís Daltoé ${ }^{1}$

Crislaine de Anunciação Roveda

Fabrício Freitas ${ }^{3}$

João Alberto da Silva ${ }^{4}$

\begin{abstract}
Resumo
A fim de investigar como ocorre o uso de tecnologias nas escolas, iniciou-se o presente Estado da Arte que se constitui como um levantamento bibliográfico das produções científicas envolvendo o uso de tecnologias no Ensino da Matemática nos Anos Iniciais do Ensino Fundamental, compreendendo portanto $1^{\circ}$ ao $5^{\circ}$ ano. O Estado da Arte compõe uma análise dos artigos científicos publicados nos últimos cinco anos, constando de 2013-2017, em quatro bases de dados: Boletim de Educação Matemática (Bolema), Associação Nacional de Pós-Graduação e Pesquisa em Educação (ANPEd), Seminário Internacional de Pesquisa em Educação Matemática (SIPEM) e o Encontro Nacional de Educação Matemática (ENEM). O corpus inicial da pesquisa é constituído por 2155 artigos. Após a primeira triagem pelo título e palavras chaves dos artigos foi possível selecionar 68 artigos. Na segunda triagem a partir da leitura dos resumos, foi possível destacar 6 deles. A terceira triagem, com a leitura completa dos artigos, constatou-se que somente 4 artigos que eram pertinentes a pesquisa, pois abordavam a utilização de tecnologias digitais como meio pedagógico de ensinar a matemática nos anos iniciais do Ensino Fundamental. Dentre os 4 podemos definir temas centrais das pesquisa: 1) cinema e videoclipe, numa perspectiva de performance matemática digital (PMD); 2) calculadora e 3) software educativo.
\end{abstract}

Palavras-chave: Tecnologias, Anos Iniciais, Ensino Fundamental, Matemática

\section{Resumen}

Con la finalidad de investigar cómo ocurre el uso de tecnologías en las escuelas, se inició el presente Estado del Arte que se constituye como un levante bibliográfico de las producciones científicas desarrollando el uso de tecnologías en la Enseñanza de Matemáticas en los Años Iniciales do Nivel Primario, comprendiendo, por lo tanto, del $1^{\circ}$ al $5^{\circ}$ año. El Estado del Arte compone un análisis de los artículos científicos publicados en los últimos cinco años, de 2013-2017, en cuatro bases de datos: Boletín de Educación Matemática (Bolema), Asociación Nacional

\footnotetext{
1 Mestranda pelo Programa de Pós Graduação em Educação em Ciência: Química da Vida e Saúde pela Universidade Federal do Rio Grande- FURG. Rio Grande - RS, Brasil. thaisdaltoe@ furg.br

2 Doutoranda pelo Programa de Pós Graduação em Educação em Ciência: Química da Vida e Saúde pela Universidade Federal do Rio Grande-FURG. Pelotas - RS, Brasil. crislaine@ furg.br

3 Doutorando pelo Programa de Pós Graduação em Educação em Ciência: Química da Vida e Saúde pela Universidade Federal do Rio Grande- FURG. Pelotas - RS, Brasil. fabriciofreitas@ furg.br

${ }^{4}$ Professor Dr. pela Universidade Federal do Rio Grande- FURG. Pelotas - RS, Brasil. joaosilva@ furg.br
} 
de Postgrado y Pesquisa en Educación (ANPEd), Seminario Internacional de Pesquisa en Educación Matemática (SIPEM) y el Encuentro Nacional de Educación Matemática (ENEM). El corpus inicial de la pesquisa es constituido por 2155 artículos. Pasada esta primera clasificación por el título y palabras claves de los artículos fue posible seleccionar 68 artículos. En la segunda etapa, desde la lectura de los resúmenes, fue posible dar destaque a 6 unidades. La tercera clasificación, con su lectura completa, se verificó que solamente 4 artículos eran pertinentes a la pesquisa, pues abordaban el uso de tecnologías digitales como recurso pedagógico para la enseñanza de matemáticas en los años iniciales del Nivel Primario. Entre los 4 podemos definir temas centrales de las pesquisas: 1) cine y videoclip, en una perspectiva de performance matemática digital; 2) calculadora y 3 ) software educativo.

Palabras Claves: Tecnologías, Años Iniciales, Nível Primario, Matemáticas.

\begin{abstract}
In order to investigate how the use of technologies in schools occurs, the present State of the Art began as a bibliographical survey of the scientific productions involving the use of technologies in Mathematics Teaching in the Early Years of Elementary School, thus comprising 1st to 5th years. The State of the Art compiles an analysis of the scientific articles published in the last five years, from 2013 to 2017, in four databases: Mathematics Education Bulletin (Bolema), National Association of Postgraduate Studies and Research in Education (ANPEd), International Seminar on Research in Mathematics Education (SIPEM) and the National Meetings of Mathematics Education (ENEM). The initial corpus of this research is consisted of 2,155 articles. After the first screening - by the title and key words - it was possible to select 68 articles. In the second screening, made from the reading of the abstracts, it was possible to highlight 6 of them. The third screening, made by the complete reading of the articles, showed that only 4 were suitable for the research, since they approached the use of digital technologies as pedagogical means of teaching mathematics in the early years of Elementary School. Among these four, we can define essencial themes of the research: 1) cinema and music videos, in a perspective of digital mathematical performance (PMD); 2) calculators and 3) educational softwares.
\end{abstract}

Keywords: Technologies, early years, elementary school, mathematics.

\title{
1.Introdução
}

O uso de tecnologias está cada vez mais presente em nosso meio, seja em casa, na rua, local de trabalho, porém ainda sente-se necessidade de explorarmos mais essas tecnologias em sala de aula. De forma a possibilitarmos aos alunos um novo mundo de possibilidades, um ensino mais interativo e participativo, onde podem estimular a criatividade e curiosidade, formulando perguntas e buscando respostas para elas, gerando assim um aprendizado significativo. A utilização de artefatos tecnológicos em sala de aula possibilita um maior desenvolvimento do(a) professor(a) enquanto profissional da educação. Além de garantir aos seus alunos o direito ao acesso a uma alfabetização tecnológica.

Sabe-se que o uso de artefatos tecnológicos ainda divide muitas opiniões de autores, professores, pais, assim como da direção e coordenação de escolas. Podemos encontrar posições contrárias ao seu uso por acreditar que a sua utilização irá impedir o aprendizado, ou então criar dependência desse recurso por parte dos alunos. Há ainda quem concorde com sua utilização, considerando um instrumento importante para o aprendizado. Porém sabemos que muitas vezes 
o fator econômico pode inviabilizar a utilização deste recurso por toda a população, principalmente em escolas públicas brasileiras.

Segundo Selva (2010) “a introdução de novas tecnologias na escola deve levar a reflexões sobre mudanças curriculares, novas dinâmicas da sala de aula e novos papéis a serem desempenhados pelo(a) professor(a)" (p. 12). Desse modo as mudanças só irão de fato ocorrer quando os professores e toda equipe da escola estiverem dispostos a enfrentar os riscos e dificuldades ao utilizarem de uma proposta pedagógica com os mais variados recursos tecnológicos.

De acordo com a Base Nacional Comum Curricular (2017) as experiências, e vivências que cada criança possui e constrói no decorrer de sua vida, sejam elas no contexto familiar, social ou cultural. Além de aspectos que envolvem sua interação com um grupo específico ou sua família em conjunto com os inúmeros recursos tecnológicos disponíveis e a comunicação com a sociedade irão estimular a curiosidade dos alunos, instigando a formulação de novas perguntas e a busca por respostas.

Para isso se torna fundamental que

$$
\begin{aligned}
& \text { a escola compreenda e incorpore mais as novas linguagens e seus modos de } \\
& \text { funcionamento, desvendando possibilidades de comunicação (e também de } \\
& \text { manipulação), e que eduque para usos mais democráticos das tecnologias e para uma } \\
& \text { participação mais consciente na cultura digital. Ao aproveitar o potencial de } \\
& \text { comunicação do universo digital, a escola pode instituir novos modos de promover a } \\
& \text { aprendizagem, a interação e o compartilhamento de significados entre professores e } \\
& \text { estudantes (BRASIL, 2017, p. 59). }
\end{aligned}
$$

Torna-se comum vermos cada vez mais crianças e jovens utilizando celular, tablets, computadores ou outros recursos tecnológicos. Caso não possuam acesso para comprar o seu próprio utilizam do vizinho, do amigo ou até mesmo da lan house. Há um crescente acesso desses artefatos para todos da sociedade, e as crianças principalmente estão inseridas nessa cultura. Porém cabe aos professores e também a escola viabilizar que esses recursos não sejam vistos somente pelo seu lado ruim. Muitas atividades e propostas podem ser pensadas com base nesse material, possibilitando aos alunos um leque de conhecimento e um desenvolvimento muito amplo.

A BNCC (BRASIL, 2017) aborda algumas competências específicas para a área do ensino da Matemática no Ensino Fundamental. Dentre elas podemos destacar duas "Utilizar processos e ferramentas matemáticas, inclusive tecnologias digitais disponíveis, para modelar e resolver problemas cotidianos, sociais e de outras áreas de conhecimento, validando estratégias e resultados" (BRASIL, 2017, p. 265) e "Os alunos devem dominar também o cálculo de porcentagem, porcentagem de porcentagem, juros, descontos e acréscimos, incluindo 
o uso de tecnologias digitais" (BRASIL, 2017, p. 267). Conforme podemos perceber com base nas competências apresentadas acima os documentos oficiais orientam para a utilização das tecnologias digitais nos diferentes níveis de ensino e para os mais variados conhecimentos.

Portanto cabe ao professor se adaptar e proporcionar aos alunos atividades para que desenvolvam essas competências. Com base nisso buscou-se nessa pesquisa compreender quais os trabalhos desenvolvidos nas instituições de ensino que utilizam-se das tecnologias de informação.

\section{O uso de tecnologias para o ensino de Matemática}

O presente Estado da Arte realizado com algumas bases de dados se constitui-se em um pequeno levantamento bibliográfico das produções científicas envolvendo o uso de tecnologias no Ensino da Matemática nos Anos Iniciais do Ensino Fundamental. A proposta inicial, era realizar essa pesquisa especificamente na Educação Infantil, porém no decorrer da pesquisa constatou-se que não seriam encontrados artigos para construir um estudo aprofundado sobre a questão e por fim um estado da arte. Com base nisso resolveu-se ampliar o delineamento utilizado para a pesquisa, utilizando trabalhos publicados que abordassem práticas empregadas com alunos de escolas dos Anos Inicias do Ensino Fundamental, compreendendo portanto $1^{\circ}$ ao $5^{\circ}$ ano do Ensino Fundamental. Para elaboração deste Estado da Arte, buscou-se, de acordo com Ferreira (2002, p. 257), "trazer em comum o desafio de mapear e de discutir uma certa produção acadêmica em diferentes campos do conhecimento". Portanto a pesquisa aqui descrita está relacionada com as práticas pedagógicas aplicadas no Ensino da Matemática com o uso de tecnologias digitais nos Anos Iniciais do Ensino Fundamental.

O Estado da Arte se constitui de uma análise dos artigos científicos publicados nos últimos cinco anos, constando de 2013-2017, em quatro bases de dados sendo elas: Boletim de Educação Matemática (Bolema), Associação Nacional de Pós-Graduação e Pesquisa em Educação (ANPEd) com suas reuniões a nível Nacional, Seminário Internacional de Pesquisa em Educação Matemática (SIPEM) e o Encontro Nacional de Educação Matemática (ENEM).

A escolha do Boletim de Educação Matemática se deu especialmente por ser considerada uma das revistas mais importantes na área da Educação Matemática no Brasil. Sendo um periódico nacional QUALIS A. A ANPEd engloba diversos programas de pósgraduação em educação, realizando a cada dois anos reuniões a nível Nacional. O Seminário Internacional de Pesquisa em Educação Matemática (SIPEM) e o Encontro Nacional de Educação Matemática (ENEM) entram na base de dados por serem eventos vinculados a 
Sociedade Brasileira de Educação Matemática (SBEM) contando com profissionais da área da Educação Matemática.

Para realização desta pesquisa foram analisadas as XI e XII edições do ENEM contabilizando 1729 artigos. No evento do SIPEM foi possível verificar as edições V e VI, dentro desses eventos verificou-se o GT01 de Educação Matemática nas séries iniciais do Ensino Fundamental e GT06 de Educação Matemática: novas tecnologias e Educação à distância com um total de 63 artigos. Na ANPED totalizando 58 artigos, foi verificado o GT19Educação Matemática, dentro das seguintes reuniões: $35^{\circ}$ Reunião Anual de ANPED, que ocorreu no ano de 2012 em Porto de Galinhas - PE; 36 ${ }^{a}$ Reunião Nacional da ANPED em Goiânia - GO no ano de 2013; 37 $7^{\mathrm{a}}$ Reunião Nacional da ANPED realizada em 2015 em Florianópolis - SC; $38^{\text {a }}$ Reunião Nacional da ANPED, com realização no ano de 2017 em São Luís - MA. Já na revista Bolema foi possível encontrar 305 artigos em um total de 16 edições das revistas publicadas em edição virtual, excluindo as edições especiais e em língua estrangeira.

Para análise e seleção dos artigos foram selecionados alguns critérios, dentre eles os de exclusão: ser artigo em língua estrangeira; anterior a 2012; edições especiais de revista; outras áreas do conhecimento que não fossem a Matemática; análise de materiais; resumos ou resenhas; pesquisas realizadas com professores, questionando a formação ou então opinião de cada um. Dentre os critérios de inclusão podemos citar: artigos que relatavam práticas realizadas em sala de aula, utilizando exclusivamente o uso das tecnologias para o ensino de Matemática nos Anos Iniciais do Ensino Fundamental; artigos dentro de prazo de 2012 à 2017 e que sejam artigos completos publicados.

O corpus inicial da pesquisa é constituído por 2155. Realizou-se portanto algumas triagens a fim de selecionar os artigos que melhor se encaixavam com os critérios préestabelecidos. Na primeira triagem realizada através da leitura de título e das palavras chaves dos artigos, buscou-se selecionar somente as que previamente se encaixassem no tema escolhido, foi possível selecionar 68 artigos. Com a segunda triagem efetuada a partir da leitura dos resumos, foi possível destacar 6 artigos. Na terceira triagem, foi realizada a leitura completa dos artigos, constatou-se então que somente 4 artigos seriam pertinentes a pesquisa, pois abordavamm a utilização de tecnologias digitais como meio pedagógico de ensinar a matemática nos anos iniciais do Ensino Fundamental. Dentre os 4 podemos definir temas centrais de cada pesquisa: 1) cinema e videoclipe, numa perspectiva de performance matemática digital (PMD); 2) calculadora e 3) software educativo. Com base nisso iremos 
realizar agora uma breve descrição das artigos selecionados, relacionando-os com demais autores e documentos oficiais.

\subsection{Cinema e videoclipe}

A proposta apresentada por Silva e Rodrigues (2015) em sua pesquisa expressa a relação com as Performances Matemáticas Digitais (PMD). Para os autores PMD “diz respeito ao uso das artes (performáticas) e das tecnologias digitais em Educação Matemática” (SILVA, 2015, p. 3). Os recursos mais comuns utilizados são o vídeo digital, assim como dança, teatro, poesia, música e o cinema, tornando-se uma proposta metodológica educacional.

A pesquisa foi realizada com 4 turmas de estudantes do EF I em uma escola com seus princípios e pressupostos voltados ao desenvolvimento cognitivo e espiritual de seus alunos. Fundamentada em teóricos que defendem a pedagogia de projetos assim como as inteligências múltiplas. As atividades tiveram como objetivo investigar os aspectos pedagógicos proporcionados ao engajarem os estudantes, professores na produção de Performances Matemáticas Digitais (PMD). Inicialmente buscaram investigar o ambiente multimodal para após propor a produção de narrativas matemáticas artísticas digitais.

A primeira atividade intitulada Fazendo 10, diz "respeito ao uso de manipulativos, objetos virtuais de aprendizagem e outros materiais voltados a investigação de diversificados conceitos matemáticos, dentre eles, campo aditivo e multiplicativo" (SILVA, 2015, p. 5). Por meio da atividade os estudantes podem estudar conceitos e noções de probabilidade, pares ordenados de números naturais, plano cartesiano, equações de primeiro grau, dentre outras possibilidades. Para a análise os autores dividiram os trabalhos em duas subseções, dentre elas: Fazendo 10 - Cinema e Fazendo 10 - Música e Videoclipe.

Com o Fazendo 10 - Cinema os pesquisadores tinham objetivo de oferecer aos alunos um primeiro contato com a produção de PMD, com base na exploração da atividade Fazendo 10. Para isso criaram um roteiro com aspectos fundamentais.

Silva e Rodrigues (2015) puderam concluir que a produção de PMD proporciona um bom efeito nos alunos, "efeito novidade", todos ficaram surpresos em poder explorar de maneira diferente a Matemática. Houve uma grande mobilização por parte dos professores também, pois sempre enfatizavam que a atividade era importante pois a escola defendia o desenvolvimento das inteligências múltiplas. O Fazendo 10 - Música e Videoclipe proporcionou ao estudantes a realização da gravação de uma música e um videoclipe sobre a atividade realizada anteriormente. 
Silva e Rodrigues (2015) ressaltam que a pesquisa está em fase inicial e ainda há muito o que percorrer e investigar. Além de destacar que "a emergência de um novo tipo de pensarcom-tecnologias-e-artes tem oferecido novas formas de se produzir significados e conhecimentos matemáticos e pedagógicos em Educação Matemática” (SILVA, 2015, p. 9). Por isso consideram importante explorar as formas como uma atividade pode ser interdisciplinar, neste caso utilizando o lado artístico e também da Matemática.

\section{2 $\mathrm{O}$ uso da calculadora em sala de aula}

No artigo de Lopes, Sá e Alves (2013) “A calculadora no ensino da potenciação: uma experiência no $4^{\circ}$ ano do Ensino Fundamental" podemos encontrar um exemplo de atividade para realizarmos em sala de aula com o auxílio da calculadora. Sabe-se que a potenciação é considerada um conteúdo a ser trabalhado a partir do $6^{\circ}$ ano do Ensino Fundamental. Porém "quando esta operação é introduzida pela primeira vez aos estudantes do $6^{\circ}$ ano do ensino fundamental, ocorre na maioria das vezes o processo de algoritmização, ou seja, a repetição da definição até que esta seja memorizada" (LOPES, 2013, p. 2).

Com base nisso os autores Lopes, Sá e Alves (2013) buscaram em sua pesquisa investigar as propriedades e a potencialidades do ensino da potenciação em uma turma de $4^{\circ}$ ano Ensino Fundamental com o auxílio de atividades dinâmicas, de forma não tradicional e com o auxílio da calculadora. Nos anos seguintes do $6^{\circ}$ ano o conceito de potenciação é ampliado para o contexto algébrico, mas na sua maioria seguem sendo ensinados por meio de exercícios repetitivos em sala de aula ou como atividades complementar para casa, ocasionando maior dificuldade de aprendizagem.

Para Lopes, Sá e Alves (2013) a utilização da calculadora não serve apenas para "facilitar a resolução de exercícios como, também, são essenciais para que o aluno possa fazer uma auto avaliação de seu desempenho em determinadas atividades” (p. 2). Em vista disso utilizaram-se desse artefato para realizar a pesquisa e aplicação das atividades com 27 alunos de uma turma do $4^{\circ}$ ano.

A pesquisa foi realizada em algumas etapas, sendo a primeira denominada de diagnóstico inicial, onde os pesquisadores aplicaram um questionário a fim de ver o perfil de cada estudante. Dentre os pontos relevantes desse primeiro diagnóstico, vale ressaltar que a maioria dos estudantes afirmou que estudava em casa. Além de relatarem gostar da Matemática apesar de estarem acostumados a aprender de forma tradicional, com exposição de conteúdos e 
exercícios. Junto com a primeira etapa foi realizado um pré-teste com o propósito de verificar quais os conhecimentos que os estudantes possuíam.

A segunda etapa de elaboração e aplicação das atividades, constou com um total de nove atividades onde os alunos tinham a possibilidade de discutir a respeito dos resultados obtidos com os demais colegas. Cada atividade foi pensada de acordo com o desenvolvimento da turma buscando introduzir o conceito de potenciação além de estudar as propriedades operatórias encontradas no decorrer das atividades. Lopes, Sá e Alves (2013) ressaltam que em todas as atividades os alunos tiveram um bom rendimento e até facilidade para resolver, mesmo não possuindo conhecimento sobre o conteúdo.

Em seguida os autores realizaram uma revisão das regras aprendidas sobre as propriedades operatórias da potenciação. Para isso utilizaram-se de jogos e atividades dinâmicas sem a utilização da calculadora que aprimorassem as habilidades para os cálculos nessas operações, além de promover o diálogo e a interação entre os colegas, fortalecendo ainda mais o desenvolvimento e a aprendizagem. Estimulando na prática tudo o que foi estudado no decorrer da aplicação das atividades.

Por fim Lopes, Sá e Alves (2013) puderam realizar um diagnóstico final, com a aplicação de um pós-teste com as mesmas atividades propostas no pré-teste. Para eles as atividades tiveram um efeito positivo, tanto das atividades de redescoberta como das atividades de fixação "pois os resultados foram extremamente satisfatórios por conta do percentual elevado de acertos, comprovando que o processo de ensino-aprendizagem foi bem sucedido" (LOPES, 2013, p. 11).

Cabe aqui ressaltar que com os resultados do pré-teste os autores puderam constatar que os alunos participantes da pesquisa não possuíam conhecimento sobre a potenciação e suas propriedades. Mas após as atividades com o pós-teste eles demonstraram um desempenho satisfatório quanto ao conteúdo trabalhado. "Acreditamos que o experimento com as atividades de redescoberta auxiliadas pela calculadora influenciou de forma positiva no processo de ensino-aprendizagem da potenciação e suas propriedades básicas" (LOPES, 2013, p. 14). Neste trabalho a calculadora foi chave fundamental para o andamento da pesquisa, podemos perceber que os alunos não receberam os resultados prontos.

Conforme ressalta Selva (2010) "não é todo uso da calculadora que possibilita explorações conceituais, mas, sim, situações didáticas bem planejadas com objetivos claros e procedimentos bem selecionados" (p. 10). Como podemos ver no decorrer da pesquisa de Lopes, Sá e Alves (2013) as atividades foram bem planejadas e os estudantes participaram na construção do seu próprio conhecimento, tornando-o assim mais significativo. 


\title{
2.3 Software Educativo
}

Sabe-se que nos dias atuais há um leque de recursos e artefatos disponíveis para os professores, dentre eles o uso de computadores e os mais variados tipos de softwares, além de diferentes fontes de pesquisa como a internet e outras mídias. O software educativo é um exemplo de recurso que pode ser utilizado pois auxilia na "manipulação e a representação de situações e fenômenos através de uma grande quantidade de formatos e linguagens, potencializando o trabalho do professor através das diversas possibilidades de construção de representações gráficas e visual" (CAMPÊLO, 2013, p. 1).

Campêlo e Carvalho (2013) ressaltam que o software educativo pode contribuir na promoção da interação entre alunos e principalmente a desenvolver a aprendizagem. O software da suporte ao professor, conduzindo o aluno à aprendizagem, além de favorecer na imaginação e em muitos outros aspectos, não só do aluno como também do professor. Para que isso ocorra o professor precisa se apropriar do software, compreender quais suas características e quais as atividades são possíveis de se realizar. Além de observar se o uso do software vai de encontro com seus objetivos e propostas, assim como da escola.

A pesquisa de Campêlo e Carvalho (2013) tem seu enfoque principal no uso e análise do software TinkerPlots, que foi desenvolvido para estudantes entre 10 e 14 anos.

\begin{abstract}
O software possibilita que os alunos percorram e estabeleçam relações entre diferentes momentos do tratamento de dados como: coleta, organização, formulação e teste de hipóteses sobre os dados. Assim pode-se criar gráficos e tabelas a partir de bancos dados disponibilizados no software, inserir novos dados coletados, bem como produzir relatórios com gráficos, textos e ilustrações (CAMPÊLO, 2013, p. 3).
\end{abstract}

Os autores tem como objetivo analisar o software educativo TinkerPlots a partir das estratégias de 3 estudantes do $5^{\circ}$ ano do Ensino Fundamental ao resolverem problemas que envolvessem a interpretação de gráficos. Inicialmente Campêlo e Carvalho (2013) realizaram mapeamento dos bancos de dados disponíveis no programa, em seguida ocorreu com a seleção de alguns bancos de dados para análise, considerando os temas e questões propostas.

As atividades propostas foram: "problemas de uma variável; problema de duas variáveis; problemas de análise da tendência do gráfico, isso é, a forma como as variáveis se relacionam; e problemas de construção de um novo caso" (CAMPÊLO, 2013, p. 6). Para a aplicação das atividades algumas etapas foram seguidas para um melhor desenvolvimento, sendo: $1^{\text {a }}$ ) familiarização do software, onde os alunos tiveram maior liberdade de exploração; $2^{\mathrm{a}}$ ) interpretação das situações problemas e uma entrevista final sobre a experiência com a utilização do software. 
Alguns critérios para a análise do software foram seguidos, como por exemplo as possibilidades oferecidas pela software, tipos de gráficos criados, forma de apresentação e resolução dos problemas, dentre outros. Com base nesses critério Campêlo e Carvalho (2013) puderam constatar que o software possibilitou aos alunos que selecionarem e experimentassem os dados e representassem com liberdade, de acordo com a mais adequada para o tipo de problema. Além de apontar que o aplicativo Os TinkerPlots possibilita "diferentes formas de representação de dados, bem como a promoção do enriquecimento de estratégias de resolução de problemas de tipos variados envolvendo a interpretação de gráficos (CAMPÊLO, 2013, p. 14).

Prosseguindo por essa perspectiva da utilização de softwares, em outro artigo de Campêlo e Carvalho (2013) podemos encontrar uma perspectiva de alfabetização digital a partir da utilização das Tecnologias da Informação e da Comunicação (TICs). Mais especificamente do uso do Laptop em sala de aula e o software Tux Paint, disponibilizado pelo Projeto Um Computador por Aluno (ProUCA). O ProUCA teve como objetivo incentivar professores de diferentes redes de ensino a utilizar o recurso do laptop em sala de aula como um instrumento que auxiliará na aprendizagem.

As TICs permitem aos estudantes não apenas estudar temas tradicionais de uma nova maneira, mas também explorar temas novos e trazê-los para a escola, um exemplo é a geometria fractal, bem como a computação gráfica, permitindo ao aluno trabalhar com animações, noções de espaço bidimensional, tridimensional e outros (CAMPÊLO, 2013, p. 2).

Com base nisso a presente pesquisa faz uma análise sobre as práticas realizadas e vivenciadas no decorrer do projeto. Incluindo a perspectiva de pais, alunos e professores de diferentes escolas. A pesquisa abrange um total de 8 professores e 12 alunos. Das séries iniciais do Ensino Fundamental, assim como das séries finais. No decorrer do artigo os autores apresentam também algumas atividades e práticas realizadas com uma turma pré-escolar, contemplando crianças de 5 anos.

Para Campêlo e Carvalho (2013) a utilização das TICs em sala de aula, mais especificamente nesse artigo o uso do laptop, demanda uma mudança de estratégia pedagógica para vários professores que não estão acostumados a trabalhar com esses recursos em sala de aula. Alicerçado nesse pressuposto oficinas de formação foram oferecidas para as professoras que iriam trabalhar com esse projeto. Foi durante essa formação que as autoras puderam coletar 
os dados, além das observações e filmagens das aulas das professoras. Além de questionário aplicados para os alunos e também aos pais.

Durante a formação as autoras puderam perceber que os professores estavam resistentes a formação pois necessitariam de "uma reorganização da forma de se trabalhar com os alunos e de um (re) planejamento para inserir as TICs de forma adequada nas aulas" (CAMPÊLO, 2013, p. 4). O que de certa forma os deixa inseguros, desconfortáveis de abordar determinado assunto sem ter o conhecimento necessário.

As professoras das séries iniciais possuíam maior facilidade em planejar, organizar e aplicar as atividades planejadas com o uso do computados, realizando sempre um trabalho de alfabetização digital. "Além de mostrar a importância da aritmética, em especial da numeração em várias atividades do dia a dia e da geometria, iniciando um trabalho com a resolução de problemas. E utilizar os próprios alunos para as contagens, as relações maior e menor, dentre outras" (CAMPÊLO, 2013, p. 4).

Após a formação dos professores as pesquisadoras puderam acompanhar a sala de aula, auxiliando e realizando oficinas pedagógicas que incluíssem o laptop nas suas atividades. Uma das atividades descritas por Campêlo e Carvalho (2013) ocorreu com a série pré-escolar, onde as crianças primeiro desenharam, utilizando lápis, papel, quadro e outros matérias. Logo após introduziram o uso do laptop com o software aplicativo Tux Paint, onde puderam explorar e desenhar de diversas formas.

\footnotetext{
não precisarmos deixar de lado as antigas práticas pedagógicas, no caso à utilização do caderno, mas os professores podem inserir a tecnologia, em suas práticas pedagógicas, como mais um recurso que pode motivar os alunos para determinadas atividades e auxiliar na compreensão de diversos conteúdos educacionais (CAMPÊLO, 2013, p. 14).
}

Portanto cabe inicialmente a cada professor estar disposto a modificar sua prática e se aprimorar de forma a possibilitar novas experiências para si e seus alunos. Conforme nos fala o autor não precisamos deixar de lado tudo o que fazemos ou utilizamos, somente acrescentar. Valorizando a vivência trazida pelos alunos para o cotidiano escolar, a fim de que em conjunto com a mediação da professora possa contribuir para o processo de ensino-aprendizagem.

\section{Conclusões}

Ao final desta análise considerados que dado o número elevado do corpus inicial dessa pesquisa, foi possível selecionar um número muito baixo de artigos que abordassem o uso de tecnologias para o ensino de Matemática nos Anos Iniciais do Ensino Fundamental. 
Ressaltando portanto o quanto a presença dos recursos tecnológicos em sala de aula se faz insuficiente, assim como projetos que auxiliem os professores. Como citado no decorrer deste artigo, o proposto inicialmente era utilizarmos artigos que relatassem o uso de tecnologias na Educação Infantil. Porém o único artigo que abordava a Educação Infantil em seu nível préescolar está presente neste artigo também, por contar com questões referentes aos anos iniciais do Ensino Fundamental.

Apesar dos computadores, smartphones, e outros artefatos tecnológicos estarem presentes no nosso cotidiano, ainda não chegaram de forma a acrescentar o desenvolvimento e aprendizagem dos alunos nas escolas. Segundo Borba (2012) "na escola, a alfabetização informática precisa ser considerada como algo tão importante quanto a alfabetização na língua materna e em matemática" (p. 87). Portanto cabe aos professores, assim como a direção da escola explorar a tecnologia que está presente, potencializando as atividades e valorizando ainda mais o processo de ensino-aprendizagem. Não basta somente utilizarmos os recursos como um enfeite ou passa tempo, é preciso conhecer, se aprofundar, valorizar as características e buscar a melhor forma de inseri-los em nossas escolas sempre em consonância com as propostas educacionais do estado, município ou da própria escola.

Sabe-se que existem muitos desafios para inserir a tecnologia nas escolas, dentre eles a situação econômica de cada família, ou de cada escola. Porém podemos buscar alternativas e parcerias que facilitem a aproximação dos alunos das salas de aulas. São as experiências que as crianças possuem no seu convívio família, e até mesmo na interação com os recursos tecnológicos disponíveis que estarão desenvolvendo a curiosidade, formulando novas perguntas, e principalmente indo em busca de respostas para elas. Para Borba (2012) a relação entre educação matemática e informática deve ser pensado como uma forma de transformação da prática educativa presente nos dias de hoje, e não como algo dicotômico, que irá prejudicar escola, professor, ou aluno.

Concluímos, portanto, que o uso das tecnologias como recurso educativo tem muito a acrescentar em sala de aula, não somente aos alunos, mas também a prática profissional do professor. Que precisará estar sempre se reconstruindo e buscando aprender junto com seus alunos. O fato de utilizar esses recursos em sala de aula, não significa que o professor precisa abandonar o quadro, lápis, caneta ou os outros materiais manipulativos ou didáticos que possui e utiliza em sua prática diária. Mas sim que há novas possibilidades, para novos alunos, para um novo e talvez mais dinâmico e eficiente processo de ensino-aprendizagem. 


\section{Referências}

BANDEIRA, Salete Maria Chalub. BEZERRA, Simone Maria Chalub Bandeira. BARROS, Vilma Luisa Siegloch Barros. Práticas Interdisciplinares com o Laptop UCA: partindo da alfabetização digital. Disponível em: <http://sbem.iuri0094.hospedagemdesites.ws/anais/XIENEM/pdf/1681_1936_ID.pdf> Acesso em Jan de 2019.

BORBA, Marcelo de Carvalho. PENTEADO, Miriam Godoy. Informática e Educação Matemática. 5a ed. Belo Horizonte: Autêntica Editora, 2012.

BRASIL. Ministério da Educação. Base Nacional Comum Curricular. Brasília: MEC/CNE, 2017.

CAMPÊLO, Siquele Roseane de Carvalho. CARVALHO, Liliane Maria T. Lima de. Software educativo para o ensino de estatística: analisando possibilidades a partir da interpretação de gráficos. Disponível em:

http://sbem.iuri0094.hospedagemdesites.ws/anais/XIENEM/pdf/612_614_ID.pdf > Acesso em Jan de 2019.

FERREIRA, Norma Sandra de Almeida. As Pesquisas Denominadas "Estado da Arte". Educação \& Sociedade, ano XXIII, no 79, p. 257-272, Ago/2002. Disponível em: $<$ http://www.scielo.br/pdf/es/v23n79/10857>. Acesso em out. 2018.

LOPES, Adrielle Cristine Mendello. SÁ, Pedro Franco de. ALVES, Fábio José da Costa. A calculadora no ensino da potenciação: uma experiência no $4^{o}$ do Ensino Fundamental. Disponível em: <http://sbem.iuri0094.hospedagemdesites.ws/anais/XIENEM/pdf/1540_840_ID.pdf> Acesso em Jan de 2019.

SELVA, Ana Coelho Vieira. BORBA, Rute Elizabete S. Rosa Borba. O uso da calculadora nos anos iniciais do ensino fundamental. Belo Horizonte: Autêntica Editora, 2010.

SILVA, Ricardo Scucuglia Rodrigues da. RODRIGUES, Alana Fuzaro de Barros. A Produção de Performances Matemáticas Digitais nos Anos Iniciais do Ensino. Disponível em: $<$ http://www.sbembrasil.org.br/visipem/anais/story_content/external_files/A\%20PRODUÇÃ O\%20DE\%20PERFORMANCES\%20MATEMÁTICAS\%20DIGITAIS\%20NOS\%20ANOS \%20INICIAIS\%20DO\%20ENSINO\%20FUNDAMENTAL.pdf> Acesso em Jan de 2019. 